Article

\title{
Development and Validation of an Instrument to Assess Pro-Pensity to Cosmopolitanism in Adolescence
}

\author{
Ilaria Di Maggio*(D), Sara Santilli, Maria Cristina Ginevra and Laura Nota \\ FISPPA, Department of Philosophy, Sociology, Pedagogy and Applied Psychology, University of Padova, \\ 3-I-35139 Padua, Italy; sara.santilli@unipd.it (S.S.); mariacristina.ginevra@unipd.it (M.C.G.); \\ laura.nota@unipd.it (L.N.) \\ * Correspondence: ilaria.dimaggio@unipd.it
}

Citation: Di Maggio, I.; Santilli, S.; Ginevra, M.C.; Nota, L. Development and Validation of an Instrument to Assess Pro-Pensity to Cosmopolitanism in Adolescence. Sustainability 2021, 13, 8253. https:// doi.org/10.3390/su13158253

Academic Editor: Hyo-Sun Jung

Received: 16 June 2021

Accepted: 19 July 2021

Published: 23 July 2021

Publisher's Note: MDPI stays neutral with regard to jurisdictional claims in published maps and institutional affiliations.

Copyright: (c) 2021 by the authors. Licensee MDPI, Basel, Switzerland. This article is an open access article distributed under the terms and conditions of the Creative Commons Attribution (CC BY) license (https:// creativecommons.org/licenses/by/ $4.0 /)$.
Abstract: The study was designed to provide the initial validation of the instrument "How cosmopolitan do I think I am?" to assess the propensity to cosmopolitanism in adolescents interested in reflecting about their future career choices. Two studies were carried out to test psychometric requisites of the instrument "How cosmopolitan do I think I am?" Specifically, in the first study, after developing items and examining content validity, the factorial structure and the reliability of the scale were tested. The results showed good fit indexes for a factor structure characterized by three-correlated factors and for a second order-factor structure. This last factor structure model suggests that three hypothesised factors can be considered indicators of a global dimension of cosmopolitanism. In the second study, discriminant validity was evaluated. The results confirmed that the three dimensions of cosmopolitanism are related but distinct from career adaptability (CA) and the tendency to consider systemic challenges to attain sustainable development (TCSC). Overall, the results observed supported the use of the questionnaire in career vocational guidance and counseling activities.

Keywords: cosmopolitanism; vocational guidance; assessment measure; career education; inclusive and sustainability

\section{Introduction}

Today's societies are characterized by uncertainty, complexity, globalization, and inequality. Adolescents find themselves living in these societies, and soon they will be increasingly required to discover new and creative solutions to provide inclusive, dignified, and sustainable living conditions for themselves, the planet Earth, and future generations. For these reasons, as recently argued by several scholars [1-3], adolescents will be increasingly asked, from a preventive perspective, to develop skills, competencies, and attitudes. Said skills have to be useful to address in an inclusive and sustainable way the global challenges reported in the 2030 Agenda of the United Nations [4]. Recently, the life design approach emphasized that promoting the tendency to understand and manage a complex system is the only option to design the future and address challenges. It supports people to handle global warming, economic and opportunity disparities in the world, discrimination, and environmental degradation $[1,2,5]$. Taking this into consideration, different authors suggest focusing attention on cosmopolitanism [3,6-8]. Cosmopolitanism can be defined as the propensity to move beyond local boundaries and to analyze both local and global aspects of reality. Cosmopolitanism also helps people to develop future life plans based on ability and heterogeneous, multinational, and open lifestyles. It also supports transforming contexts while respecting the residents' values, backgrounds, and civil rights $[6,9,10]$. As regards future life plans, focusing attention on the cosmopolitan vision of reality means helping adolescents to learn to manage, in their professional and personal lives, inclusively and sustainably, local circumstances generated by global aspects, local situations that 
influence global ones, as well as the absence of clear and deterministic geopolitical boundaries [11]. Moreover, focusing attention on cosmopolitanism means helping adolescents interact, both live and remotely, with people of different cultures, languages, ethnicities, and expertise, thus promoting a systematic exploration of different and useful ways of planning and actions for their personal and professional growth. It also helps them develop ideas, projects, and actions aimed at managing complex global challenges [3]. Based on the life design approach, this study aimed to validate "How cosmopolitan do I think I am?" as an instrument to assess the propensity to cosmopolitanism in adolescence, which is relevant for vocational and career issues.

Cosmopolitanism: Definitions and Conceptualizations. Ulf Hannerz [12,13] used cosmopolitanism to delineate the tendency people have to go past state boundaries, study social phenomena associated with what can be found outside one's community, and design new life plans that involve an open and multicultural way of living. Szerszynski and Urry [14,15], in line with Hannerz [12,13], considered cosmopolitanism as a cultural inclination that involves a psychological and aesthetic position of broad-mindedness toward different people, areas, and cultural backgrounds. The tendency to consider this openness as a salient component of cosmopolitanism is also found in Vertovec and colleagues' work $[8,16,17]$. They suggested a model that explained cosmopolitanism, differentiating it into five categories: socio-cultural, philosophical, political, a set of attitudes, and a set of skills. More specifically, in their definition of cosmopolitanism, the authors stated that it is connected with various characteristics. These are openness to the world, enhancement of heterogeneity, positive inclination towards different cultures, and relations with individuals with a different cultural and social experience. Therefore, Hannerz [10], Vertovec, and Cohen [17] stated that openness is seen as a key feature of cosmopolitanism that goes together with actions of exploration and connection with individuals who have a different cultural and social experience. Hannerz [10] expanded the concept of cosmopolitanism, focusing on the important role of the political aspects. Said aspects include the inclination to consider global disparities, the non-compliance with rights, the democratic deficit, and the negative impact that everything above-mentioned has on everyone's lives. The aspects as mentioned above focus on human rights, respect, tolerance, and global responsibility. In addition, Vertovec and colleagues $[8,16,17]$ dedicate their attention to the collective wellbeing that extends past state boundaries and that can bring communities together despite the different territorial contexts and situations. They also direct their attention to the ability to conceive citizenship from an other point of view, using a global and inclusive mindset that has its roots in human rights, tolerance, and global responsibility. Beck $[6,9,18]$ focuses on the habit people have to consider the local aspect of reality and the global one. A cosmopolitan attitude can be considered insightful only when attention is given to both local and global aspects. Beck affirmed that a cosmopolitan can merge the local aspects of his/her identity with global ones, is aware of national and global problems, and can restructure his/her behaviors while considering reality in its local and global aspects. It is possible to state that there are several dimensions in cosmopolitanism for which there seems to exist an agreement in literature, e.g., $[6,8,10,15]$ : (a) the propensity to have an open attitude toward the world and heterogeneity, which also involves the inclination to establish contacts with individuals that have a different cultural and social experience; (b) the inclination to examine both the "local" and the "global" sides of everyday life; (c) the inclination to focus on biodiversity, human rights, sustainability, and inclusion (the political aspects of cosmopolitanism).

Regarding the relationship between cosmopolitanism and sustainability, several scholars emphasize that the tendency to take a cosmopolitan perspective of reality can help achieve goals aimed at building more inclusive and sustainable future societies [6-8,19-21]. Specifically, as argued by Rendtorff [19], solving current global challenges related to the environment, economy, and social sustainability requires a tendency to consider the consequences of events and actions from a local and a global perspective. 
Moreover, the ethical and political values associated with cosmopolitan citizenship are linked to social sustainability as they focus on respect for human rights, diversity, and each individual's uniqueness [19]. Sáiz [20] emphasized, for the same reasons as Rendtorff [19], that the idea of ecological citizenship may be regarded as a kind of cosmopolitan or global citizenship. Finally, Grinstein and Riefler [21] showed that highly cosmopolitan consumers showed environmental concern and engaged in sustainable behavior. As far as concerns the contribution of cosmopolitanism in the adolescents' life design processes focused on building more inclusive and sustainable future societies, this has only recently been emphasized within the life design for an inclusive and sustainable future.

Life Design Paradigm and Cosmopolitanism to Design an Inclusive and Sustainable Future for All. The life design paradigm, centered on social constructivism [22], highlighted that career development is highly contextualized and individualized. Said paradigm conceptualizes for individuals with and without disability and vulnerability, e.g., $[23,24]$ career development as an active synergy between personal characteristics and contextual aspects. In particular, this paradigm states that singular subjects are operating agents and actors of their personal and professional growth, of their present and future, by planning their life stories and defining consistent life objectives and plans $[25,26]$. The person is not designed by the context but is in interdependence with it. Recently, based on the life design approach and considering the new global challenges that characterize today's world and societies, several scholars have suggested that career guidance should promote abilities, competencies, and attitudes that can help adolescents to consider global challenges in their career planning to move towards an inclusive and sustainable global development $[5,27]$. In this perspective, it may be important to involve cosmopolitanism in the future life design process because it could help adolescents move towards a more satisfactory personal and professional future that is also more oriented towards creating an inclusive and sustainable future society [3,6-8,19-21]. Specifically, the propensity to have an open attitude to the world and to heterogeneity and the propensity to establish contacts with people of different cultures, religions, and national origins could help adolescents to transform the heterogeneity of contexts from a potential threat into a "possibility in their future planning" [3]. The attention shared between the local and the global could be relevant for career guidance as it could allow adolescents to take a flexible and complex view on reality that is useful to understand global challenges, their possible consequences, and the validity and effectiveness of possible resolving actions [11]. Finally, the attention to universal rights, the common good, solidarity, sustainability, and inclusion could be translated into educational and career choices oriented to become "active agents" of political change in support of inclusive and sustainable societies and, for this reason, of extreme importance in inclusive and sustainable career guidance [1,11].

Cosmopolitanism: Studies and Assessment Instruments. One of the first scales developed to assess cosmopolitanism was the "Local Cosmopolitanism Scale" [28], which is composed of five items and aimed to distinguish between local and cosmopolitan persons by assessing their interest in the local community activities. On the other hand, Jenning's [29] measure aimed —with three items — to analyze cosmopolitanism's trend by evaluating the individuals' orientation toward multiple levels of government. Robinson and Zill's [30] scale, composed of five items, focused attention to assessing cosmopolitanism on attitudes toward wide cultural and political matters, like attitudes toward modern art or teaching foreign languages. Jain and Etgar's [31] scale-composed on six itemsfocused on interest regarding world happenings to assess cosmopolitanism. Riefler and Diamantopoulos [32] pointed out that these scales developed between 1963 and 1997 do not present adequate validity and reliability indexes. Moreover, although they assess a key feature of cosmopolitanism, their use allows the measurement of only a single aspect of cosmopolitanism. Efforts towards developing multifactorial measures of cosmopolitanism were made by Earle and Cvetkovich [33] and by Yoon et al. [31]. These scales have been developed and used in marketing contexts. Specifically, Earle and Cvetkovich's [33] scale of cosmopolitanism involves five items for assessing five dimensions: interpretation of 
culture, community, identity, order, and commonalities. Yoon et al. [34] developed the CYMYC scale composed of 24 items that assess four different factors of cosmopolitan behavior: (1) search and evaluation of decision-related information, (2) organizational cosmopolitanism, (3) communication behavior, and (4) hunger for diversity. Riefler and Diamantopoulos [32] asserted that the scale developed by Earle and Cvetkovich [33] included difficult-to-read items (as some of them were composed of several sentences). In addition, according to scholars, the CYMYC scale [34] showed poor psychometric requirements. Moreover, as Riefler and Diamantopoulos [32] suggested, this instrument is unsuitable for being used in other contexts of investigation except in the marketing context.

Aim of the Research. This study aimed to test psychometric requisites of the instrument "How cosmopolitan do I think I am?" which was designed to assess cosmopolitanism in career guidance. In this situation, it is fundamental to consider the expanding enthusiasm focused on cosmopolitanism as regards career guidance and the absence of accurate and solid tools of investigation to evaluate it for teenagers. Specifically, this instrument aimed to examine three central dimensions of cosmopolitanism that are relevant to vocational guidance and career design. Said dimensions are (a) the propensity to have an open attitude to the world and heterogeneity; (b) the propensity to consider both the "local" and the "global" aspects of reality; (c) the propensity to give attention to biodiversity, human rights, sustainability, and inclusion. With this aim, using the test theory approach [35], two studies using independent samples were carried out. The first study was aimed to generate items for the three dimensions of cosmopolitanism and test item appropriateness and understandability. It also aimed to examine the scale's factor structure using item analysis, exploratory factor analysis (EFA), and confirmatory factor analysis (CFA). The second study aimed to test discriminant validity using correlations analysis. Considering the relevance of the relational, cultural, and political environment in cosmopolitanism [3,6-8], we predicted that, in particular, the three dimensions of cosmopolitanism were significantly and positively related with the "curiosity" dimension of career adaptability (CA), which regards the tendency to explore the self and the environment in career designing [36] and the tendency to consider systemic challenges to attain a sustainable development (TCSC) [3].

\section{Method}

\subsection{Participants}

In the first study, 520 adolescents from 16 to 19 years old $(\mathrm{M}=17.27, \mathrm{SD}=0.82)$ of which 242 (46.5\%) were boys and 278 (53.5\%) were girls, were involved. Participants were randomly assigned to subsample A and subsample B. Specifically, subsample A, which involved 200 high school students (92 boys and 108 girls), with a mean age of 17.35 years $(\mathrm{SD}=0.75)$, was employed to carry out EFA. The subsample B, which involved 320 high school students (150 boys and 170 girls), with a mean age of 17.22 years $(\mathrm{SD}=0.85)$, was employed to carry out CFA. Between the two samples no gender $(\chi 2(1)=0.038$, $p=0.857)$ and age $(\mathrm{t}(518)=1.86, p=0.064)$ differences were found. In the second study, 100 adolescents from 16 to 19 years old $(M=17.51, S D=0.99)$, of which 42 were boys and 58 were girls, were involved.

\subsection{Measure}

How Cosmopolitan Do I Think I Am? Based on recommendations suggested by Clark and Watson [37], a team of two experts (first and fourth author) produced 16 items to assess the three different components of cosmopolitanism: (a) propensity to assume an openness to the world and to heterogeneity; (b) propensity to consider both the "local" and the "global" aspects of reality; (c) propensity to give attention to biodiversity, human rights, sustainability, and inclusion. To test if the items developed were appropriate and understandable by high school students, a Flesch-Kincaid test and a pilot study involving 20 Italian adolescents (10 boys and 10 girls) (Mage $=17, \mathrm{SD}=0.65$ ) were carried out. The 16 items showed a Flesch-Kincaid grade level of 15.17, which confirmed that the items 
were applicable for adolescents. The preliminary version of the instrument was used in both studies. Respondents were required to read the following instructions and indicate the extent to which each item describes their current way of thinking and behaving on a five-point scale ( 1 = describes barely at all my thoughts and behavior; $5=$ describes perfectly my thoughts and behavior).

Career Adapt-Abilities Scale-Italian Form [38] was used-in study two-to evaluate the CA total score. Specifically, this measure is composed by 24 items to assess 4 dimensions of CA: concern (e.g., "realizing that today's choices shape my future"; $\alpha=0.80$ ), control (e.g., "sticking up for my beliefs"; $\alpha=0.74$ ), curiosity (e.g., "investigating options before making a choice"; $\alpha=0.77$ ), and confidence (e.g., "taking care to do things well"; $\alpha=0.85$ ). The scale showed good reliability and validity indices. In this study, Cronbach's alpha for the four dimensions were $0.86,0.79,0.82$, and 0.79 , respectively. The Cronbach's alpha for the CA total score was 0.92 .

The future is around the corner... what will it hold for us? An instrument on UN's goals for the inclusive and sustainable development [3]. This scale was used to analyze TCSC. Specifically, this scale is composed by 17 items, describing the 17 goals presented in the 2030 Agenda for Sustainable Development. An example of an item is: "Surely in the future there will still be a lot to do in order to put an end to all kind of malnutrition in the world ... How much could the goal of nourishment and of availability of safe and healthy food affect your future educational and career choices?" Adolescents were invited to answer by referring to a 5 -point Likert scale $(1=$ too little, $5=$ very much). The scale showed good reliability and validity indices. In this study, Cronbach's alpha was 0.90.

\subsection{Procedure}

In both studies, a multi-stage sampling method was used e.g [39,40]. Specifically, different Veneto high schools were randomly selected to participate in a vocational career guidance research project. Subjects were randomly selected the 11th- and 12th-grade classes interested in taking part in the research project. Within each chosen class, every student was allowed to join the project after acquiring parental consent (for students under 18 years). Thus, the totality of the students involved spontaneously chose to join the project. All the students involved, and their parents were told, through informed consent, about the project and research goal. The career counselor also explained that all personal data are protected by professional confidentiality, following ethical procedures ruled by the Italian Ethical Principles of Psychologists.

\subsection{Results and Discussion}

In the first study, using subsample A, preliminary analyses to test skew, kurtosis, and inter-item correlations were carried out. The analysis showed adequate skew, kurtosis, and correlation index $(r \leq 0.70)$, and consequently no items were removed. In the second step, EFA with a direct oblimin rotation was executed. Considering Bartlett's test of sphericity $(p<0.001)$ and the Kaiser-Meyer-Olkin measure (0.92), the 16 items were suitable for EFA. All criteria considered to select the adequate number of factors—such as scree plot [41] and Kaiser-Guttman criterion [42,43]—recommended an initial three-factor solution. Moreover, no cross-loadings and primary factor loadings below 0.40 were found. The three-factor oblique solution (16 items) accounted for $54 \%$ of the total variance (see Table 1). Specifically, the first factor composed by 10 items aimed to assess the propensity to assume an openness to the world and to heterogeneity and accounted for $31.46 \%$ of the variance. The second factor composed by 3 items aimed to assess the propensity to consider both the "local" and the "global" aspects of reality and accounted for $10.04 \%$ of the variance. The third factor composed by 3 items aimed to assess the propensity to give attention to biodiversity, human rights, sustainability, and inclusion and accounted for $12.42 \%$ of the variance. Factor loadings ranged from 0.40 to 0.77 , and communality values were greater than 0.20 for all items (see Table 1). 
Table 1. Items, component loading, and communality estimates.

\begin{tabular}{|c|c|c|c|c|}
\hline Items & Factor 1 & Factor 2 & Factor 3 & Communality \\
\hline 10. I like learning more about different situations and lifestyles. & 0.84 & -0.05 & 0.03 & 0.71 \\
\hline $\begin{array}{l}\text { 15. I look for and establish relationships with people with } \\
\text { different traditions and lifestyles. }\end{array}$ & 0.80 & 0.02 & 0.06 & 0.72 \\
\hline $\begin{array}{l}\text { 11. I feel pleasure in nurturing my traditions and at the same } \\
\text { time I feel attracted by different ones. }\end{array}$ & 0.78 & -0.04 & -0.03 & 0.55 \\
\hline $\begin{array}{l}\text { 4. I like reading about scenarios, environments and cultures that } \\
\text { are very different from the ones I am used to. }\end{array}$ & 0.77 & -0.07 & -0.05 & 0.51 \\
\hline $\begin{array}{l}\text { 5. I like interacting with people who remind me how much our } \\
\text { planet is diverse. }\end{array}$ & 0.74 & -0.05 & 0.13 & 0.66 \\
\hline $\begin{array}{l}\text { 16. I like learning about objects and materials that characterize } \\
\text { the differences of our planet. }\end{array}$ & 0.68 & 0.02 & 0.02 & 0.49 \\
\hline $\begin{array}{l}\text { 8. I often interact and keep in touch with people coming from } \\
\text { different parts of the world. }\end{array}$ & 0.59 & 0.26 & 0.02 & 0.58 \\
\hline 1. I like getting in touch with different cultures and traditions. & 0.56 & 0.32 & -0.06 & 0.52 \\
\hline 2. I like surrounding myself with people with different interests. & 0.46 & 0.09 & 0.16 & 0.40 \\
\hline $\begin{array}{l}\text { 9. I like working with people who, even when they do not share } \\
\text { my opinion, "root" also for others. }\end{array}$ & 0.41 & 0.01 & 0.26 & 0.34 \\
\hline $\begin{array}{l}\text { 3. I like getting familiar with the idea that I could work in Italy, } \\
\text { but also in other European countries, or in New York, Beijing, } \\
\text { Moscow, or Rio de Janeiro. }\end{array}$ & 0.03 & 0.93 & -0.07 & 0.84 \\
\hline $\begin{array}{l}\text { 7. I always feel like I am "transient," even where I live, as if my } \\
\text { true home was a world without borders. }\end{array}$ & 0.04 & 0.40 & 0.20 & 0.29 \\
\hline $\begin{array}{l}\text { 13. I am happy of feeling a citizen of my own town and at the } \\
\text { same time "of the world." }\end{array}$ & 0.12 & 0.40 & 0.27 & 0.44 \\
\hline $\begin{array}{l}\text { 12. I openly defend the universal right, as reported in the } \\
\text { Universal Declaration of Human Rights, "to leave any country, } \\
\text { including his own, and to return to his country" (art. 13). }\end{array}$ & -0.06 & 0.15 & 0.80 & 0.67 \\
\hline $\begin{array}{l}\text { 14. I pay attention to the differences of people and places in } \\
\text { order to give the same rights to everybody. }\end{array}$ & 0.06 & -0.02 & 0.68 & 0.52 \\
\hline $\begin{array}{l}\text { 6. I like protecting biodiversity, even if it means having to give } \\
\text { up to something. }\end{array}$ & 0.15 & -0.08 & 0.56 & 0.41 \\
\hline
\end{tabular}

A CFA was performed with sample B. Different indexes and criteria were used for the estimation of the model fit: (1) chi-square statistics, (2) the comparative fit index (CFI), (3) the non-normed fit index (NNFI), (4) the root mean square error of approximation (RMSEA), and (5) the standardised root mean squared residual (SRMR). CFI and NNFI values superior to 0.95 and RMSEA and SRMR values superior to 0.08 can be judged statistics of good model fit [44].

Using a competing model strategy, the hypothesized three-factor correlated model (Model A) was compared with Model B (the unidimensional model) and Model C (the second-order-factor model). This latter model (Model C) was expected considering the common variance shared by the three first-order factors and because a propensity to assume an openness to the world and to heterogeneity, a propensity to consider both the "local" and the "global" aspects of reality, and a propensity to give attention to biodiversity, human rights, sustainability, and inclusion can be considered - from a theoretical point of view-as the three dimensions of an overarching construct that is cosmopolitanism. The three-factor correlated model (Model A: 16-3) showed good fit: $\chi 2(101$, n. 320) $=257,966, p<0.001$; $\mathrm{CFI}=0.969 ; \mathrm{NNFI}=0.963 ; \mathrm{RMSEA}=0.069(\mathrm{CI} 90=0.059-0.080) ; \mathrm{SRMR}=0.051$. All factor loadings ranged from 0.47 to 0.78 and were significant $(p<0.001)$. Moreover, $\mathbf{R}^{2}$ values were greater than $20 \%$ and ranged between 0.22 to 0.60 . These indexes may be considered adequate [41]. The unidimensional one-factor model (Model B: 16-1) did not show good fit indexes: $\chi 2(104, \mathrm{n} .320)=341.198, p<0.001 ; \mathrm{CFI}=0.957 ; \mathrm{NNFI}=0.950$; RMSEA $=0.085$ $(\mathrm{CI} 90=0.075-0.095) ; \mathrm{SRMR}=0.057$. Moreover, the $\chi 2$ difference test suggested that the three-factor correlated model (Model A: 16-3) did improve the fit compared with the Model B $\Delta \times 2(3)=83.23, p<0.05$. Moreover, using the CFI $\Delta$ test, CFI changes were 0.012 
between the two models. Thus, the three-factor correlated model is better supported. The second-order-factor model (Model C: 16-3-1) showed the same degrees of freedom and chi-square of Model A. In addition, the three first-order factors significantly saturated on the second-order factor. Specifically, standardized loadings of first-order factors were 0.90 for a propensity to assume an openness to the world and to heterogeneity, 0.95 for a propensity to consider both the "local" and the "global" aspects of reality, and 0.85 for a propensity to consider both the "local" and the "global" aspects of reality. These results suggest that three factors can be considered as indicators of a global dimension reflecting propensity to cosmopolitanism. Internal consistency (sample B). Cronbach's $\alpha$ internalconsistency reliability was 0.87 for a propensity to assume an openness to the world and to heterogeneity, 0.65 for a propensity to consider both the "local" and the "global" aspects of reality, 0.74 for a propensity to give attention to biodiversity, human rights, sustainability and inclusion, and 0.90 for a propensity to cosmopolitanism as a global dimension.

In the second study, correlations between the total score and the three dimensions of cosmopolitanism (propensity to assume an openness to the world and to heterogeneity, propensity to consider both the "local" and the "global" aspects of reality, and propensity to give attention to biodiversity, human rights, sustainability and inclusion) and the four dimensions of CA (concern, control, curiosity, and confidence) and the TCSC were tested. As shown in Table 2, weak to moderate positive correlations were found between the three dimensions of the cosmopolitanism, curiosity (factor of CA), and the TCSC ( $\mathrm{r}$ from 0.20 to 0.50 ) Moreover, a propensity to assume an openness to world and to heterogeneity positively correlated with the confidence (factor of CA). Finally, the total score of the cosmopolitanism scale positively correlated ( $\mathrm{r}$ from 0.29 to 0.45 ) with curiosity and the TCSC. These results confirmed that the three dimensions of cosmopolitanism are related but distinct from CA and TCSC, suggesting that adolescents with higher levels of cosmopolitism are characterized also for more CA, in particular, curiosity and confidence, and more TCSC.

Table 2. Correlations among cosmopolitism, TSCS, and CA.

\begin{tabular}{|c|c|c|c|c|c|}
\hline & TCSC & Concern & Control & Curiosity & Confidence \\
\hline $\begin{array}{l}\text { Propensity to assume an openness to the } \\
\text { world and to heterogeneity }\end{array}$ & $0.44^{* *}$ & 0.10 & 0.18 & $0.30^{* *}$ & $0.20^{*}$ \\
\hline $\begin{array}{l}\text { Propensity to consider both the "local" and } \\
\text { the "global" aspects of reality }\end{array}$ & $0.50^{* *}$ & 0.17 & 0.19 & $0.25^{*}$ & 0.11 \\
\hline $\begin{array}{l}\text { Propensity to give attention to biodiversity, } \\
\text { human rights, sustainability and inclusion. }\end{array}$ & $0.20^{*}$ & 0.11 & 0.08 & $0.30^{* *}$ & 0.12 \\
\hline Cosmopolitism total score & $0.45^{* *}$ & 0.13 & 0.18 & $0.33^{* *}$ & 0.18 \\
\hline
\end{tabular}

Note: ${ }^{* *}$ Correlations were significant at $p<0.01 .{ }^{*}$ Correlations were significant at $p<0.05$.

\subsection{General Discussion}

This study aimed to test psychometric requisites of the instrument "How cosmopolitan do I think I am?" to assesse cosmopolitanism in adolescents. Unlike existing measures, the measure "How cosmopolitan do I think I am?" allowed us to assess three dimensions of cosmopolitanism in the field of career guidance. The two studies conducted showed that the questionnaire "How cosmopolitan do I think I am?" is a valid and reliable instrument to analyze three different dimensions of cosmopolitanism. These dimensions are a propensity to assume an openness to the world and to heterogeneity, a propensity to consider both the "local" and the "global" aspects of reality, a propensity to give attention to biodiversity, human rights, sustainability, and inclusion. In addition, the questionnaire allowed us to assess a general dimension of propensity to cosmopolitanism. Regarding the construct validity of the instrument as shown in study 1 , a factor structure of instruments characterized by three correlated factors was supported by EFA and CFA. More specifically, the CFA confirmed the structure of the three-factor correlated model and the second-order factor model. This last model is also plausible and suggests that the propensity to assume an openness to the world and to heterogeneity, to consider both the "local" and the "global" 
aspects of reality, and to give attention to biodiversity, human rights, sustainability, and inclusion can be considered as indicators of cosmopolitanism. Moreover, the analyses carried out showed good scale reliability. These results were in line with different authors that conceptualized cosmopolitanism as a multidimensional construct $[8,16,17]$ that involves different dimensions such as propensity to assume an openness to world and to heterogeneity, that is, carried out in actions of exploration and contact with individuals that have a different cultural and social experience $[10,14]$, propensity to consider both the "local" and the "global" aspects of reality $[6,9,18]$, and propensity to give attention to biodiversity, human rights, sustainability, and inclusion $[8,10]$. In the second study, the discriminant validity of the scale "How cosmopolitan do I think I am?" was analyzed using correlations analysis. The correlation indexes obtained showed the three dimensions of cosmopolitanism and its total score correlated with CA and TCSC, suggesting that adolescents with higher levels of cosmopolitanism are characterized by more CA and particular curiosity and confidence and TCSC. These results were in line with different authors that assumed how cosmopolitanism can be relevant in the future life design process for adolescents [3,6-8]. Specifically, as expected, these results suggest that cosmopolitanism, and its openness towards heterogeneity and diversity, is positively related to curiosity to explore the environment, which can be useful in the career decision-making process [36]. Moreover, the propensity to assume an openness to world and to heterogeneity is positively related with the tendence to recognize skills to face problems and challenges (confidence). These results suggest how openness to diversity allows individuals to act with a greater sense of effectiveness in complex and heterogeneous social contexts [3]. In conclusion, overall, the results of the current study provide new information about cosmopolitanism in adolescents and emphasize the relevance of studying cosmopolitanism in this developmental period, given the relevant role it plays in an inclusive and sustainable future life design [3].

Practical Implications. The results obtained in the two different studies carried out supports the use of "How cosmopolitan do I think I am?" in career vocational guidance and counseling procedures aimed to help youth in the process of future life designing and to promote personal and career abilities useful to move toward an inclusive and sustainable society [3]. This instrument could help analyze adolescents' propensity to cosmopolitanism. It could also be used to verify the efficacy of career guidance activities aimed at developing cosmopolitanism and adolescents' tendency to consider the global challenges in their future life designing. Finally, it could be used in research to examine relations between cosmopolitanism and other relevant dimensions in career guidance issues.

Limitations and Directions for Future Studies. Further studies should consider participants' ethnicity, which was not considered in the present study. Furthermore, convergent and incremental validity of the instrument was not tested. With this aim, additional study is needed to investigate the relations among these instruments and other measures aimed to assess propensity to cosmopolitanism. Lastly, in future research, a multitrait and multimethod design should be used to test how self-report and informant-report scores correlate, and test-retest measures and the measurement invariance across gender should also be introduced.

\section{Conclusions}

Considering the relevance of studying, analyzing, and implementing cosmopolitanism in life design processes focused on building more inclusive and sustainable future societies, this study aimed to analyze the psychometric requirements of the instrument "How cosmopolitan do I think I am?" The results obtained in the two studies conducted showed that the instrument "How cosmopolitan do I think I am?" is a valid and reliable measure to assess cosmopolitanism as a global dimension but also to assess specific aspects of cosmopolitanism such as the propensity to assume an openness to the world and to heterogeneity, the propensity to consider both the "local" and the "global" aspects of reality, and the propensity to give attention to biodiversity, human rights, sustainability, and inclusion. Furthermore, this instrument can be useful to analyze adolescents' propensity 
to cosmopolitanism in vocational and career activities and to verify the efficacy of career guidance activities aimed at developing cosmopolitanism and the tendency of adolescents to consider the global challenges in their future life designing.

Author Contributions: Conceptualization, I.D.M.; Formal Analysis: I.D.M.; Methodology, I.D.M. and S.S.; Writing review and editing: S.S. and M.C.G.; Supervision, L.N. All authors have read and agreed to the published version of the manuscript.

Funding: This research received no external funding.

Data Availability Statement: Not applicable.

Conflicts of Interest: The authors declare no conflict of interest.

\section{References}

1. García-Feijoo, M.; Eizaguirre, A.; Rica-Aspiunza, A. Systematic Review of Sustainable-Development-Goal Deployment in Business Schools. Sustainability 2020, 12, 440-459. [CrossRef]

2. Guichard, J. Life Design interventions and the issue of work. In Interventions in Career Design and Education: Transformation for Sustainable Development and Decent Work; CohenScali, V., Pouyaud, J.P., DrabikPodgorna, M., Aisenson, G., Bernaud, J.L., Guichard, J.V., Eds.; Springer: Paris, France; Cham, Switzerland, 2018; pp. 15-28.

3. Nota, L.; Soresi, S.; Di Maggio, I.; Santilli, S.; Ginevra, M.C. Sustainable Development, in Career Counseling and Career Education; Springer: London, UK, 2020.

4. United Nations. The Sustainable Development Agenda. 2015. Available online: https://www.un.org/sustainabledevelopment/ development-agenda/ (accessed on 23 July 2021).

5. Di Maggio, I.; Ginevra, M.C.; Santilli, S.; Nota, L.; Soresi, S. The Role of Career Adaptability, the Tendency to Consider Systemic Challenges to Attain a Sustainable Development, and Hope to Improve Investments in Higher Education. Front. Psychol. 2020, 11, 1926. [CrossRef]

6. Beck, U. Methodological Cosmopolitanism. In Democracy: A Reader; Blaug, R., Schwarzmantel, J., Eds.; Columbia University Press: New York, NY, USA, 2016; pp. 463-467.

7. Holton, R.J. Cosmopolitanisms, New Thinking and New Directions; Palgrave Macmillan: New York, NY, USA, 2009.

8. Vertovec, S. An accented radio: Fostering cosmopolitanism through media in Berlin. In Cosmopolitanism in Practice; Nowicka, M., Rovisco, M., Eds.; Routledge: London, UK, 2016; pp. 131-144.

9. Beck, U. Cosmopolitan Vision; Polity press: Cambridge, UK, 2006.

10. Hannerz, U. Cosmopolitanism. In A Companion to the Anthropology of Politics; Nugent, D., Vincent, J., Eds.; Blackwell: Oxford, UK, 2004; pp. 69-85.

11. Della Porta, D.; Diani, M. Social Movements: An Introduction; John Wiley Sons: Hoboken, NJ, USA, 2020.

12. Hannerz, U. Cosmopolitans and locals in world culture. Theory Cult. Soc. 1990, 7, 237-251. [CrossRef]

13. Hannerz, U. Transnational Connections: Culture, People, Places; Routledge: London, UK, 1996.

14. Szerszynski, B.; Urry, J. Visuality, mobility and the cosmopolitan: Inhabiting the world from afar. Br. J. Sociol. 2006, 57, 113-131. [CrossRef] [PubMed]

15. Szerszynskiand, B.; Urry, J. Cultures of cosmopolitanism. Sociol. Rev. 2002, 50, 455-481. [CrossRef]

16. Vertovec, S. Cosmopolitanism in Attitude, Practice and Competence. 2009. Available online: https://pure.mpg.de/rest/items/ item_1126666/component/file_2056850/content (accessed on 23 July 2021).

17. Vertovec, S.; Cohen, R. (Eds.) Introduction: Conceiving cosmopolitanism. In Conceiving Cosmopolitanism: Theory, Context, and Practice; Oxford University Press: New York, NY, USA, 2002; pp. 1-22.

18. Beck, U. The cosmopolitan society and its enemies. Theory Cult. Soc. 2002, 19, 17-44. [CrossRef]

19. Rendtorff, J.D. Philosophy of Management and Sustainability: Rethinking Business Ethics and Social Responsibility in Sustainable Development; Emerald Group Publishing: Bingley, UK, 2019.

20. Valencia Sáiz, Á. Globalisation, cosmopolitanism and ecological citizenship. Environ. Politics 2005, 14, 163-178. [CrossRef]

21. Grinstein, A.; Riefler, P. Citizens of the (green) world? Cosmopolitan orientation and sustainability. J. Int. Bus. Stud. 2015, 46, 694-714. [CrossRef]

22. Nota, L.; Rossier, J. Handbook of Life Design: From Practice to Theory and from Theory to Practice; Hogrefe: Göttingen, Germany, 2015.

23. Di Maggio, I.; Montenegro, E.; Little, T.D.; Nota, L.; Ginevra, M.C. Career Adaptability, Hope, and Life Satisfaction: An Analysis of Adults with and Without Substance Use Disorder. J. Happiness Stud. 2021. [CrossRef]

24. Di Maggio, I.; Santilli, S.; Nota, L.; Ginevra, M.C. The predictive role of self-determination and psychological empowerment on job satisfaction in persons with intellectual disability. Adv. Neurodev. Disord. 2019, 3, 197-203. [CrossRef]

25. Wehmeyer, M.L.; Nota, L.; Soresi, S.; Shogren, K.A.; Morningstar, M.E.; Ferrari, L.; Di Maggio, I. A crisis in career development: Life designing and implications for transition. Career Dev. Transit. Except. Individ. 2019, 42, 179-187. [CrossRef]

26. Di Maggio, I.; Shogren, K.A.; Wehmeyer, M.L.; Nota, L. Self-determination and future goals in a sample of adults with intellectual disability. J. Intell. Disabil. Res. 2020, 64, 27-37. [CrossRef] [PubMed] 
27. Pouyaud, J.; Guichard, J. A twenty-first century challenge: How to lead an active life whilst contributing to sustainable and equitable development. In Career Guidance for Social Justice; Hooley, T., Sultana, R.G., Thomsen, R., Eds.; Routledge: London, UK, 2017; pp. 31-45.

28. Dye, T.R. The local-cosmopolitan dimension and the study of urban politics. Soc. Forces 1963, 41, 239-246. [CrossRef]

29. Jennings, M.K. Pre-adult orientations to multiple systems of government. Midwest J. Political Sci. 1967, 11, 291-317. [CrossRef]

30. Robinson, J.P.; Zill, N. Matters of culture. Am. Demogr. 1997, 19, $24-27$.

31. Jain, A.K.; Etgar, M. Overlap in retail outlet and product innovator characteristics. J. Retail. 1977, 53, 63-74.

32. Riefler, P.; Diamantopoulos, A. Consumer cosmopolitanism: Review and replication of the CYMYC scale. J. Bus. Res. 2009, 62, 407-419. [CrossRef]

33. Earle, T.C.; Cvetkovich, G. Culture, cosmopolitanism, and risk management. Risk Anal. 1997, 17, 55-65. [CrossRef]

34. Yoon, S.J.; Cannon, H.M.; Yaprak, A. Evaluating the CYMYC cosmopolitanism scale on Korean consumers. Adv. Int. Mark. 1996, 7, 211-232.

35. Nunnally, J.C.; Bernstein, I.H. Psychometric Theory; McGraw-Hill: New York, NY, USA, 1994.

36. Savickas, M.L.; Porfeli, E.J. Career Adapt-Abilities Scale: Construction, reliability, and measurement equivalence across 13 countries. J. Vocat. Behav. 2012, 80, 661-673. [CrossRef]

37. Clark, L.A.; Watson, D. Constructing validity: Basic issues in objective scale development. Psychol. Assess. 1995, 7, 309-319. [CrossRef]

38. Soresi, S.; Nota, L.; Ferrari, L. Career Adapt-Abilities Scale-Italian Form: Psychometric properties and relationships to breadth of interests, quality of life, and perceived barriers. J. Vocat. Behav. 2012, 80, 705-711. [CrossRef]

39. De Carlo, N.A.; Robusto, E. Teoria e Tecniche di Campionamento Nelle Scienze Sociali [Theory and Methods of Sampling in the Social Sciences]; LED: Milano, Italy, 1996.

40. Dudovskiy, J. An Ultimate Guide to Writing a Dissertation in Business Studies: A Step-by-Step Assistance. [ResearchMethodology.net Version], 4th ed. 2018. Available online: https://research-methodology.net/about-us/ebook/ (accessed on 23 July 2021).

41. Cattell, R.B. The scree test for the number of factors. Multivar. Behav. Res. 1966, 1, 245-276. [CrossRef] [PubMed]

42. Guttman, L. Some necessary conditions for common-factor analysis. Psychometrika 1954, 19, 149-161. [CrossRef]

43. Kaiser, H.F. The application of electronic computers to factor analysis. Educ. Psychol. Meas. 1960, 20, 141-151. [CrossRef]

44. Schermelleh-Engel, K.; Moosbrugger, H.; Müller, H. Evaluating the fit of structural equation models: Tests of significance and descriptive goodness-of-fit measures. Methods Psychol. Res. Online 2003, 8, 23-74. 